\title{
CHEMICAL PRECIPITATION AND COATINGS OF TIN SELENIDE
}

\author{
Z. Zainal*, N. Saravanan, K. Anuar, M.Z. Hussein \\ Department of Chemistry, University Putra Malaysia \\ 43400 Serdang, Selangor, Malaysia
}

W.M.M. Yunus

Department of Physics, Universiti Putra Malaysia, 43400 Serdang, Selangor, Malaysia

Received 28 August 2002, Accepted 7 November 2003

\begin{abstract}
Tin selenide were prepared chemically in alkaline aqueous solution. The crystalline powder was coated onto microscope glass slides using polyvinyl alcohol solution. The coatings were subjected to annealing at various temperatures to study the effect towards the structure, morphology and composition of the material. The product prepared was characterised using various techniques. The photoresponse for the samples were also studied. The photoelectrochemical (PEC) cell configuration was $p$-SnSe $\mid\left(0.01 \mathrm{M} \mathrm{K}_{4} \mathrm{Fe}(\mathrm{CN})_{6}-0.01 \mathrm{M} \mathrm{K}_{3} \mathrm{Fe}(\mathrm{CN})_{6} \cdot 3 \mathrm{H}_{2} \mathrm{O}-0.1 \mathrm{M} \mathrm{Na}_{2} \mathrm{SO}_{4} \mid \mathrm{Pt}\right)$.
\end{abstract}

\section{INTRODUCTION}

In recent years, the synthesis and characterisation of metal chalcogenides of different groups have attracted considerable attention due to their brilliant application prospects. These compounds are reported to be used as sensor and laser materials, thin films polarizers and thermoelectric cooling materials ${ }^{1}$. They also possess certain criteria to make them potential candidates in photoelectrochemical (PEC) solar cells. These materials are usually prepared through electrochemical and chemical deposition method and are quite attractive for designing systems for electro-optics and PEC solar cells. Improvements in process reproducibility laid the groundwork for introducing a new product, which is composed of several innovative materials and methods. An intensive research and development phase is the key to clarify important factors for module efficiency, environmental stability and production yield ${ }^{2}$.

Considerable attention has been given by various authors in the preparation techniques of tin selenide ( $\mathrm{SnSe}$ ) films. Among the methods used are chemical bath deposition ${ }^{3}$, vacuum evaporation, chemical vapour deposition ${ }^{4-12}$ and electrodeposition ${ }^{13,14}$. SnSe is a narrow band

Corresponding author e-mail: zulkar@fsas.upm.edu.my 
gap binary IV-VI semiconductor displaying a variety of applications as essential material in photoelectrochemical solar cells to suppress the photocorrosion and to enhance the fill factor in electrical switches and in junction devices ${ }^{12}$. Thin films of tin selenide $(\mathrm{SnSe})$ are also used in infrared optoelectronic devices and memory switching devices ${ }^{13}$. In this paper, the properties of SnSe prepared by chemical precipitation followed by brush coating using polyvinyl alcohol solution as a binder was studied.

\section{METHODOLOGY}

All the reagents were of Analar grade and used as purchased. Tin selenide precipitation was carried out by mixing alkaline solutions of Sn-EDTA and elemental selenium. Sn-EDTA solution was prepared from $\mathrm{Na}_{2}$ EDTA. $2 \mathrm{H}_{2} \mathrm{O}$ and $\mathrm{SnCl}_{2} \cdot 2 \mathrm{H}_{2} \mathrm{O}$. Sn-EDTA stabilised $\mathrm{Sn}^{2+}$ from further oxidation and ensure slow release of $\mathrm{Sn}^{2+}$ ions into the reaction bath. The alkaline selenium solution was prepared by mixing elemental $\mathrm{Se}$ with excess $\mathrm{NaOH}$ solution. The addition of $\mathrm{NaOH}$ initiated the dissolution of elemental Se. The mixture was stirred rapidly to ensure complete Se dissolution. Upon mixing with Sn-EDTA solution a dark grey precipitate was formed. This precipitate was filtered and washed with excess water. The powder obtained was stirred together with polyvinyl alcohol solution (PVA) 5\% w/w, to form a SnSe-PVA mixture. The mixture was later brush coated onto microscope glass slides and dried for $12 \mathrm{~h}$. The microscope slides was washed in concentrated $\mathrm{HNO}_{3}$ and distilled water prior to use. Effects of annealing were carried out for $30 \mathrm{~min}$ in $\mathrm{N}_{2}$ atmosphere at different temperatures (100, 150 and $\left.200^{\circ} \mathrm{C}\right)$.

X-ray diffraction (XRD) analysis was carried out using a Siemens D-5000 Diffractometer for the $2 \theta$ ranging from $2^{\circ}-6^{\circ}$ with $\mathrm{CuK} \alpha(\lambda=1.5418 \AA)$ radiation. Scanning electron microscopy (SEM) and energy dispersive analysis of X-ray (EDX) was performed on a JEOL JSM 6400 Scanning Microscope. Photo responsiveness of the samples were tested in $\left.\left[\mathrm{Fe}(\mathrm{CN})_{6}\right]^{3-} / \mathrm{Fe}(\mathrm{CN})_{6}\right]^{4-}$ redox system, by running linear sweep voltammetry (LSV) between -0.40 to $-1.00 \mathrm{~V}$. An EG \& G Princeton Applied Research potentiostat driven by a software model 270 Electrochemical Analysis System was used to control the LSV process and to monitor the current and voltage profiles. The system consists of SnSe-PVA coating on indium doped tin oxide (ITO) glass as a working electrode, platinum and $\mathrm{Ag} / \mathrm{AgCl}$ as the counter and reference electrodes. The photocurrent (Ip) and darkcurrent (Id) of the PEC cells were recorded under dark and light illumination using a tungsten-halogen lamp (100 W).

\section{RESULTS AND DISCUSSION}

Figure 1 shows the XRD pattern of the SnSe crystalline powder obtained. The peaks in the pattern indicate the formation of orthorhombic phase of SnSe. The results are well matched with the standard JCPDS values (File No. 32-1382) for SnSe (Table 1). 


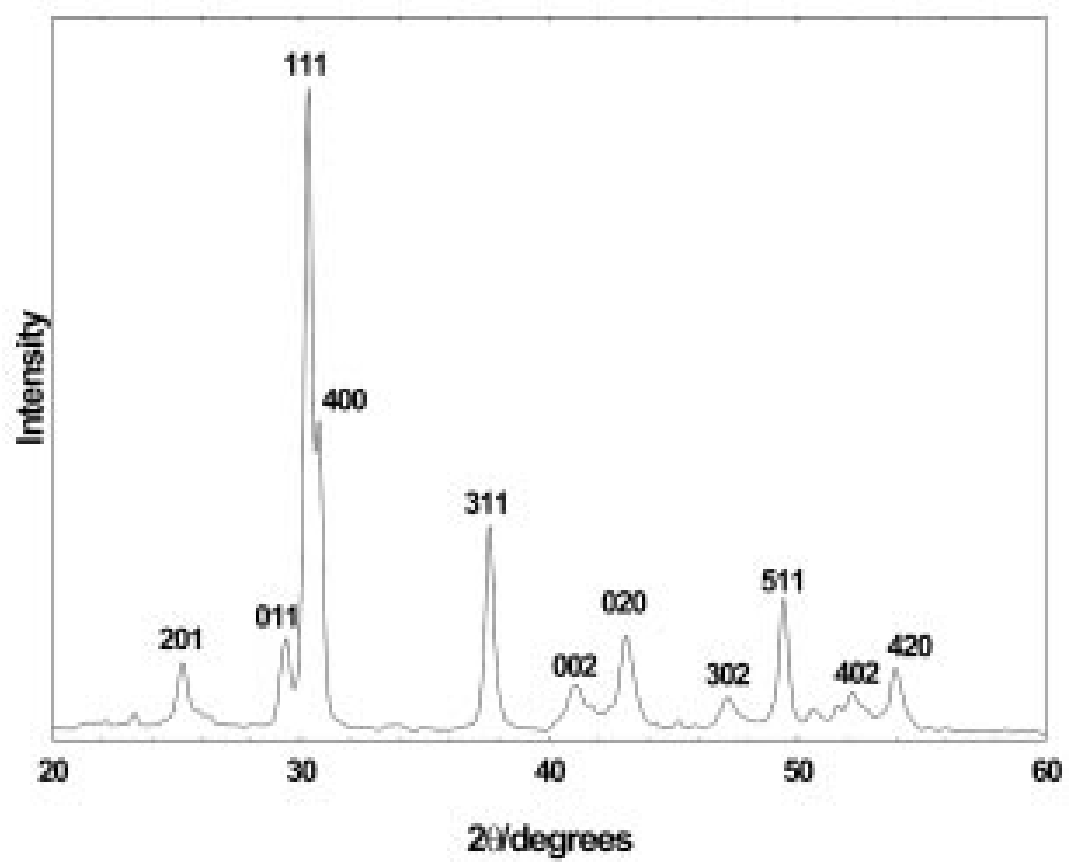

Figure 1: XRD pattern of SnSe powder

Table 1: Comparison between d values of SnSe powder and JCPDS data

\begin{tabular}{ccc}
\hline \multirow{2}{*}{$\theta$ (degrees) } & \multicolumn{2}{c}{$\boldsymbol{d}$-spacing } \\
\cline { 2 - 3 } & Obtained values & $\begin{array}{c}\text { JCPDS values } \\
\text { (File No. 32-1382) }\end{array}$ \\
\hline 25.2 & 3.53 & 3.52 \\
29.3 & 3.04 & 3.05 \\
30.2 & 2.94 & 2.94 \\
37.5 & 2.39 & 2.38 \\
43.0 & 2.09 & 2.09 \\
49.3 & 1.84 & 1.83 \\
53.9 & 1.69 & 1.68 \\
\hline
\end{tabular}

The dissolution of elemental Se in alkaline solution and the formation of SnSe could be explained as below:

$$
\begin{gathered}
3 \mathrm{Se}+6 \mathrm{NaOH} \rightarrow 2 \mathrm{Na}_{2} \mathrm{Se}+\mathrm{Na}_{2} \mathrm{SeO}_{3}+3 \mathrm{H}_{2} \mathrm{O} \\
\mathrm{Na}_{2} \mathrm{Se}+\mathrm{Sn}-\text { EDTA } \rightarrow \mathrm{SnSe}+\mathrm{Na}_{2} \text { EDTA }
\end{gathered}
$$


$\mathrm{Na}_{2}$ EDTA $2 \mathrm{H}_{2} \mathrm{O}$ was used to promote tin complex ions, in order to ensure slow release of $\mathrm{Sn}^{2+}$ ions into the reaction bath, leading to the formation of tin selenide. If $\mathrm{SnCl}_{2} \cdot 2 \mathrm{H}_{2} \mathrm{O}$ was directly used, it could be hydrolysed in aqueous solution and produce a precipitate of $\mathrm{Sn}(\mathrm{OH}) \mathrm{Cl}$. In the meantime it would also produce tin oxides in alkaline solutions. The formation of tin complex avoids the occurrence of these impurities. From the XRD pattern, no peaks corresponding to Se could be seen. This indicates that the sample powder contains no elemental Se. The concentration of $\mathrm{NaOH}$ has to be high enough (10-12 M) for the formation of SnSe. Low concentration of $\mathrm{NaOH}$ could not dissolve the elemental Se completely and thus the product may contain Se as an impurity.

Figure 2 shows the XRD patterns of the SnSe-PVA coatings annealed at different temperature. Annealing improved the crystalline phase of PVA but did not induce any structural changes in SnSe. The annealed coatings exhibited five peaks attributed to SnSe compared to four peaks for the sample that was not annealed. These corresponds to 201, 111, 311, 020 and 511 planes.

Figure 3 shows the SEM micrographs of the SnSe-PVA coatings that underwent heat treatment at different temperatures. The untreated sample shows small grains of the SnSe material distributed over the substrate surface. The size of the material varies from one another. The coating that was annealed at $100^{\circ} \mathrm{C}$ indicate better morphology compared to the untreated sample. The grain size of SnSe material is much bigger and has complete coverage of the substrate surface. Similar appearance is also observed in the coating that was annealed at $150^{\circ} \mathrm{C}$. However, as the annealing

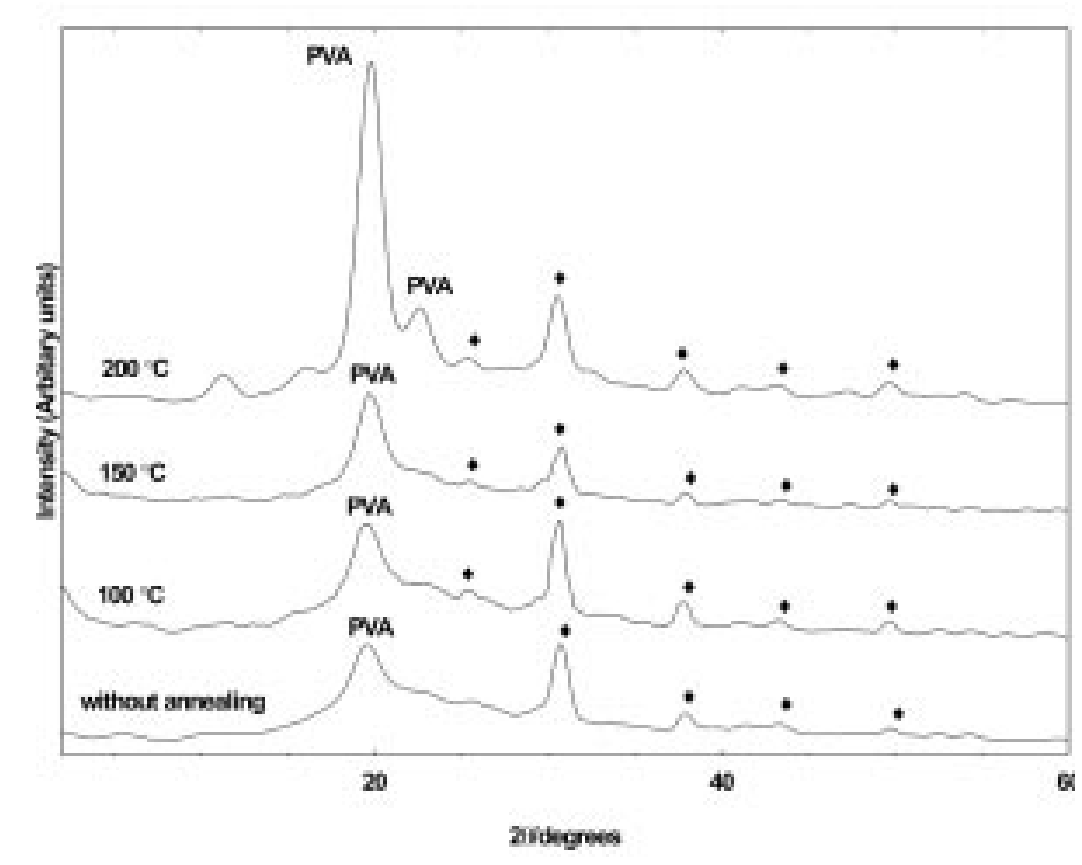

Figure 2: XRD patterns of coatings annealed at different temperature. Polyvinyl alcohol (PVA); SnSe (•) 
temperature was increased to $200^{\circ} \mathrm{C}$, hairline cracks seems to appear on the PVA surface. This indicates that annealing at higher temperature damages the surface of the binder. Table 2 shows the ratio of $\mathrm{Sn}$ to $\mathrm{Se}$ obtained from the EDX analysis. The results indicate that the composition of $\mathrm{Sn}$ to $\mathrm{Se}$ is almost stoichiometric for all the coatings prepared except the sample annealed at $200^{\circ} \mathrm{C}$.

Table 2 : Sn to Se ratio of the coatings

\begin{tabular}{cc}
\hline Samples & Sn/Se ratio \\
\hline Untreated sample & 1.1 \\
Annealed at $100^{\circ} \mathrm{C}$ & 1.0 \\
Annealed at $150^{\circ} \mathrm{C}$ & 0.9 \\
Annealed at $200^{\circ} \mathrm{C}$ & 0.8 \\
\hline
\end{tabular}

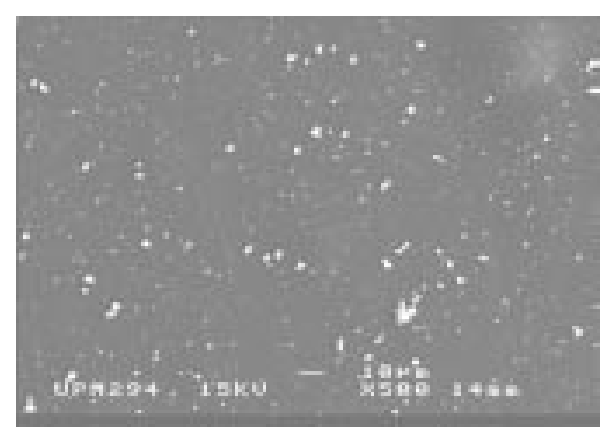

(a)

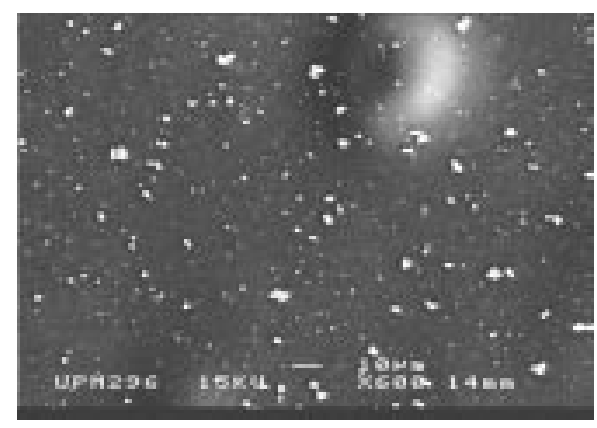

(c)

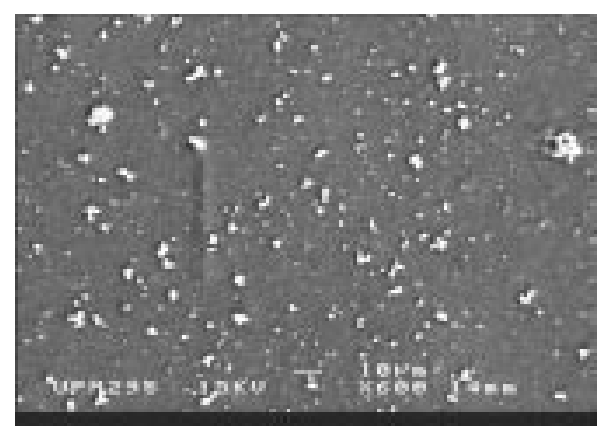

(b)

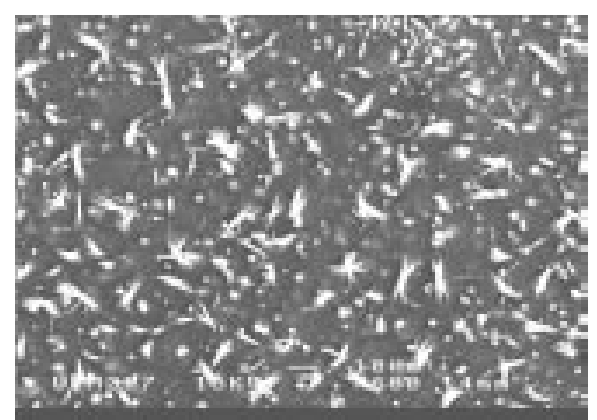

(d)

Figure 3 : SEM micrographs of SnSe coatings annealed at different temperature; without annealing (a), $100^{\circ} \mathrm{C}(b), 150^{\circ} \mathrm{C}(\mathrm{c})$ and $200^{\circ} \mathrm{C}(d)$. 


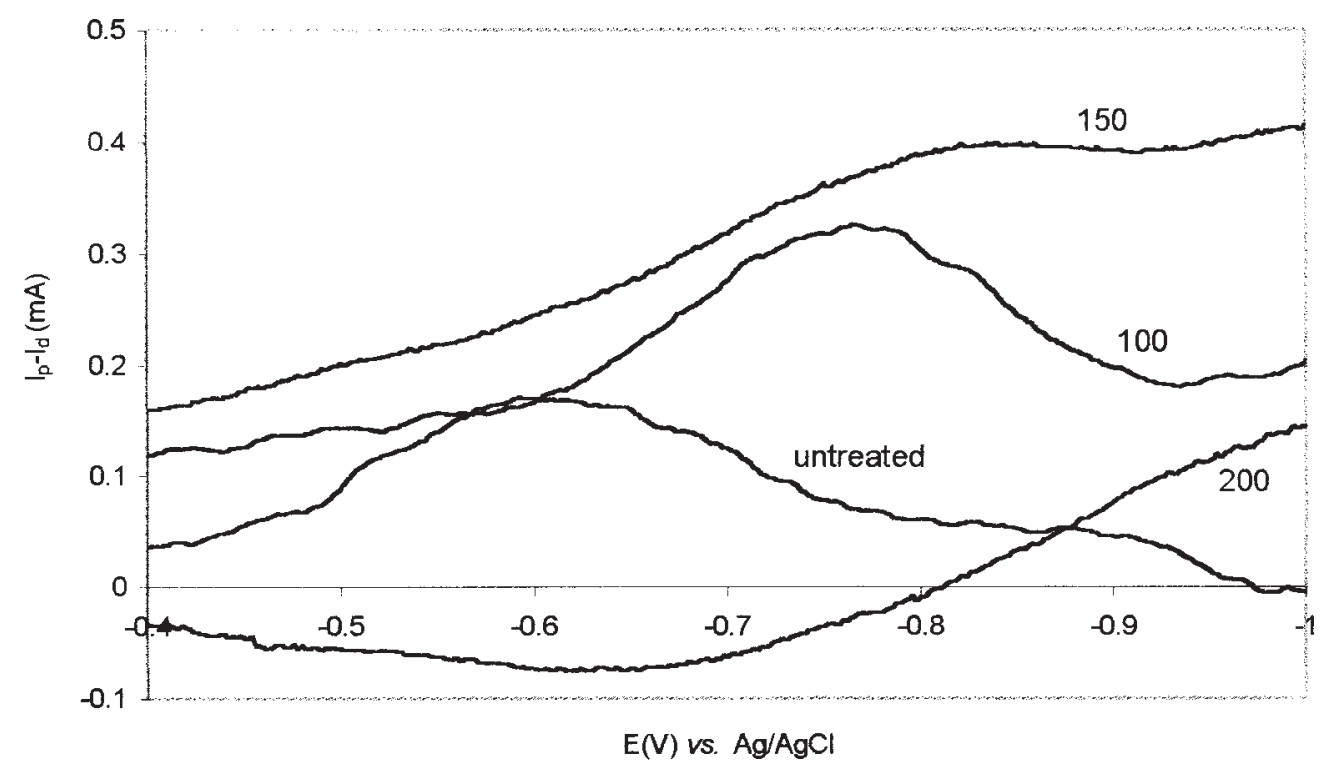

Figure 4: Difference between photocurrent (Ip) and darkcurrent (Id) for the samples

Figure 4 indicates the difference between the photocurrent and darkcurrent response for the coatings in $\left.\left[\mathrm{Fe}(\mathrm{CN})_{6}\right]^{3-} / \mathrm{Fe}(\mathrm{CN})_{6}\right]^{4-}$ redox system. The coating that was annealed at $150^{\circ} \mathrm{C}$ shows the best photoresponse compared to the other treated and untreated samples. A steady increase in the current could be observed for the sample annealed at $150^{\circ} \mathrm{C}$, which was employed as a cathode in the electrochemical cell as the potential is swept to more negative region. Comparison between the untreated coating and the coatings treated at 100 and $150^{\circ} \mathrm{C}$ indicate a steady increase in the photoresponse. This indicates that annealing promotes incipient fusion of small crystallites and thereby reduces the grain boundaries, which are known to act as recombination centres for minority carriers and trapping centres for majority carriers. This current change with the illumination confirms that the films posses semiconducting behaviour. The fact that the photocurrent occur on the negative (cathode) potential indicates that the films prepared are of $p$-type (positive) and they can be deployed as photo cathode in the PECs application to facilitate a reduction reaction of the electroactive species in the solution. The photoresponse for the sample annealed at $200^{\circ} \mathrm{C}$ decreased gradually. The decrease in the photoresponse could be due to the appearance of cracks observed from the SEM micrographs. This physical change on the surface of the coating could effects the binding properties of SnSe-PVA and finally disrupts the photoresponse on the SnSe material.

\section{CONCLUSION}

Polycrystalline SnSe powder could be obtained using the method explained. Annealing the coatings at different temperature changes the properties of the material. Annealing at $150^{\circ} \mathrm{C}$ was found to be an optimum condition for the SnSe coatings. Annealing above $150^{\circ} \mathrm{C}$ damages the surface of PVA, which reduces the photosensitivity of SnSe. 


\section{ACKNOWLEDGEMENTS}

This work was supported by the IRPA Grant No. 09-02-04-0369-EA001. One of the co-authors (N.S.) would like to thank the Ministry of Science, Technology and Environment for the scholarship.

\section{REFERENCES}

1. Zweibel, K. (2000), Sol. Energy Mat. Sol. Cells, vol. 63, pp.375-386.

2. Karg, F.H. (2001), Sol. Energy Mat. Sol. Cells, vol. 66, pp. 645-653.

3. Pramanik, P. and Bhattacharya S. (1988), S.J. Mater. Sci Let., vol. 7, pp. 1305-1309.

4. John, J., Pradeep, B. and Mathai, E. (1994) J. Mater. Sci., 29, pp.1581-1585.

5. Bennouna, A., Tessier, P., Priol, M., Dang, T.Q. and Robin, S. (1983), phys. stat. sol. (b) vol. 117, no. 51-56.

6. Dang, T.Q. (1984) Phys. Stat. Sol. (a), vol 86, pp. 421-426.

7. Rao, T.S. and Chaudhuri, A.K. (1985) J. Phys. D: Appl. Phys., vol. 18, pp. L35-L40.

8. Rao, T.S., Samanthary, B.K. and Chaudhuri, A.K. (1985) J. Mater. Sci. Lett., vol. 4, pp. 743-745.

9. Dang, T.Q. (1987) Thin Solid Films, vol. 149, pp. 197-203.

10. Sharon, M. and Basavaswaran, K. (1987), Solar Cells, vol. 20, pp. 323-332.

11. Singh, J.P. and Bedi, R.K. (1990), Jap. J. Appl. Phys., vol. 29, no. 6, pp. L869-L871.

12. Suguna, P., Mangalaraj, D., Narayandass, S.A.K. and Meena, P. (1996), phys. stat. sol. (a) 1996, vol. 155, pp. 405-416.

13. Subramanian, B., Mahalingam, T., Sanjeeviraja, C., Jayachandran, M. and Chockalingam, M.J. (1999), Thin Solid Films, vol. 357, pp. 119-124.

14. Engelken, R.D., Berry, A.K., Van D. T.P., Boone, J.L. and Shahnazary, A. (1986), J. Electrochem. Soc., vol. 133, pp. 581-584. 